\title{
(Re)descobrindo Saussure no Ensino de Língua Portuguesa: práticas de letramentos à luz dos signos saussurianos
}

\author{
Julio Cesar Machado ${ }^{1}$ \\ Livian Aparecida Corsi Machado ${ }^{2}$
}

\begin{abstract}
RESUMO
$\mathrm{O}$ objeto de estudo dessa pesquisa desenha-se no imbricamento entre a teoria saussuriana do signo e os processos de letramento na aula de língua portuguesa. Neste vértice, propomos nossa maximus hipotesis: revisitar a teoria saussuriana, de aprofundamento imperativo no Brasil, refletindo-a enquanto procedimentos de letramento. Procederemos analiticamente por uma abordagem de metodologia bibliográfica, de cunho teórico e teor qualitativo: nossos dados, de cunho indagatórios, serão operados respaldados em duas obras teóricas póstumas de Saussure: Cours de Linguistique Générale, sem precedentes da aplicação profunda à área do ensino; e a muito recente publicação dos Écrits de Linguistique Générale, ainda desconhecida ou sequer abordada no cenário pedagógico brasileiro, e por isso, de necessidade reflexiva imperiosa nas dimensões da alfabetização e letramento brasileiros. Os resultados analíticos apontam para a eficácia da teoria saussuriana enquanto procedimentos para letramentos em aulas de língua portuguesa, e suscitam a perspectiva de outras pesquisas exploratórias nessa direção.
\end{abstract}

PALAVRAS-CHAVE: Saussure. Ensino de línguas. Signo. Letramento.

(Re)discovering Saussure in Portuguese Language Teaching: literacy practices based on Saussurean signs

\footnotetext{
${ }^{1}$ Doutor. Universidade do Estado de Minas Gerais, Belo Horizonte, Minas Gerais, Brasil. https://orcid.org/00000003-0364-3370.julio.machado@uemg.br.

2 Mestranda. Universidade do Estado de Minas Gerais, Belo Horizonte, Minas Gerais, Brasil. Financiamento FAPEMIG 11392 PAG-Educação. https://orcid.org/0000-0002-3929-8989. livian.machado@gmail.com.
} 


\begin{abstract}
The object of study of this research is drawn in the overlap between the Saussurean theory of the sign and the literacy processes in the Portuguese language class. At this point, we propose our maximus hypotesis: revisiting Saussurean theory, of imperative deepening in Brazil, reflecting it as literacy procedures. We will proceed analytically by an approach of bibliographic methodology, of theoretical and qualitative content: our data, of questioning nature, will be operated supported in two posthumous theoretical works of Saussure: Cours de Linguistique Générale, without precedents of the deep application to the teaching area; and the very recent publication of the Écrits de Linguistique Générale, still unknown or even addressed in the Brazilian pedagogical scenario, and therefore, of imperative reflexive need in the dimensions of Brazilian literacy and literacy. The analytical results point to the effectiveness of Saussurean theory as procedures for literacies in Portuguese language classes, and raise the prospect of other exploratory research in this direction.
\end{abstract}

KEYWORDS: Saussure. Language teaching. Sign. Literacy.

(Re) descubriendo Saussure en la enseñanza de la lengua portuguesa: prácticas de letramiento basadas en signos saussurianos

\title{
RESUMEN
}

El objeto de estudio de esta investigación se dibuja en la superposición entre la teoría saussuriana del signo y los procesos de alfabetización en la clase de lengua portuguesa. En este punto, proponemos nuestra hipotesis máxima: revisar la teoría saussuriana, de profundización imperativa en Brasil, reflejándola como procedimientos de letramiento. Procederemos analíticamente mediante un enfoque de metodología bibliográfica, de contenido teórico y cualitativo: nuestros datos, de naturaleza cuestionadora, serán operados apoyados en dos trabajos teóricos póstumos de Saussure: Cours de Linguistique Générale, sin precedentes de la aplicación profunda al área de enseñanza; y la publicación muy reciente de Écrits de Linguistique Générale, aún desconocida o incluso abordada en el escenario pedagógico brasileño y, por lo tanto, de 
necesidad reflexiva imperativa en las dimensiones de la alfabetización y la alfabetización brasileñas. Los resultados analíticos apuntan a la efectividad de la teoría saussuriana como procedimientos para la alfabetización en las clases de lengua portuguesa, y plantean la posibilidad de otra investigación exploratoria en esta dirección.

PALABRAS CLAVE: Saussure. Enseñanza de idiomas. Signo. Letramiento.

\section{Introdução}

Esta pesquisa, de caráter introdutório, concretizou-se a partir do debate em dois espaços científicos internacionais: na École des Hautes Études en Ciences Sociales, em Paris, França, e na Universidade do Estado de Minas Gerais, Brasil ${ }^{3}$, nos últimos 7 anos. Nestes dois espaços, diagnosticamos e refletimos uma lacuna brasileira e francesa no que tange à relação entre Linguística e Ensino: certo isolamento considerável entre esses dois saberes. A praxe de conhecimento desses saberes tem mostrado ser natural que o primeiro se debruce sobretudo sobre preocupações e produções teóricas, e o segundo, sobre preocupações e produções práticas. O diálogo necessário entre praxe de ensino e abstração teórico-linguística acaba por não se concretizar, em muitos projetos e pesquisas. É nesta lacuna que se inscreve este trabalho.

Já é convenção entre expoentes mundiais da Linguística e da Educação que "o processo de alfabetização é, também, e essencialmente, um processo de natureza linguística” (SOARES, 2003, p. 21). Nossas reuniões em instituições francesas e brasileiras destacaram a seguinte problemática: o que há é mais o isolamento entre os saberes da Linguística e Educação, e menos o imbricamento dinâmico entre eles para refletir os processos de

\footnotetext{
${ }^{3}$ Expressamos gratidão pelo financiamento das agências de Fomento CAPES-PDSE; SRE-MG; FESP-MG; PAEXUEMG e FAPEMIG, por financiar nossas pesquisas no Brasil e na França.
} 
aprendizagem de uma língua. E isto não se trata de um diagnóstico apenas teórico. Ao contrário, o abismo entre estas duas áreas científicas acarreta prejuízos impactantes para o processo de letramento/aquisição da linguagem ${ }^{4}$.

Este hiato entre Linguística/Educação merece discussão no cenário acadêmico se observamos o seguinte panorama científico brasileiro: muito se tem publicado, no acervo científico de revistas científicas brasileiras, sobre "contribuições" "da” Linguística "para" "a” Educação. Estas aspas mostram o efeito de sentido de mão única produzido em abordagens de vários artigos: um movimento metodológico epistêmico apenas de ida, de uma só direção: “contribuição de X para Y" (donde Y parece se preservar de X, ou donde X parecer ter apenas função instrumental para validação de $\mathrm{Y}$, dentre outros efeitos). Ademais, o que se chama de "contribuições" é um hiperônimo vagamente trabalhado, pois em muitos trabalhos, a tal "contribuição" possui mais uma função de ratificação que de fato investigação. $\mathrm{O}$ que temos, em muitas publicações brasileiras, não se trata, portanto, de análise entre/intra áreas - interdisciplinar, mas de uso instrumental de uma área para ratificar outra - uso pluridisciplinar e estratégico de ratificação.

Mesmo que a Linguística goze de um apreço nobre na grande área do Ensino, na efetivação das publicações de teor educacional ${ }^{5}$ (nos muitos modos como a Linguística adentra e participa de um texto sobre Educação, por exemplo), observa-se que a palavra "contribuição" não é aleatória: ela é fartamente usada por pesquisadores da Educação no Brasil, produzindo o efeito de que a Linguística tem sido um saber quase isolado a ser consultado, um saber que não se filia à Educação, mas que é por ela vista com bons olhos. Um saber que a ela não pertence na linha histórico-epistemológica,

\footnotetext{
${ }^{4}$ Esta pesquisa tem consonância teórico-científica com a dicotomia que tem se tornado clássica nos estudos educacionais: "Alfabetização e Letramento", mesmo que não se fizesse tal distinção na época da elaboração teórica de Saussure. O leitor atento perceberá que muito desses dois conceitos têm presença na noção saussuriana de "linguagem" (que é um conceito mais rico do que se pensa no Brasil), justamente por carregar em si e instaurar na comunidade falante, e nos procedimentos de aprendizagem das línguas, a dinâmica entre o social (a língua) e o individual (fala), próprias do Letramento.

${ }^{5}$ Não cremos ser conveniente, para os propósitos deste artigo, produzir aqui um sumário de publicações nas quais se observa este efeito lacunar de isolar Linguística e Educação. Por isso nos reservaremos deste gesto.
} 
mas tem um fim estratégico de ser apropriado vez ou outra para ratificar e autorizar reflexões e análises que se debruçam sobre o objeto da Linguagem na área da Educação.

Evidentemente, não podemos esquecer de levar em conta a exímia destreza de alguns autores (poderíamos citar um rol razoável de excelentes trabalhos que constroem esta interação) que constroem coerentemente este panorama interdisciplinar Linguística-Ensino ${ }^{6}$. Contudo são parcas, e até raras, no Brasil, as publicações que analisam por indissocialidade tais campos, de modo dinâmico e interconstitutivo, o fenômeno educacional entre estas duas áreas. Talvez pela disposição das universidades brasileiras, que não incentivam uma dupla formação (ou se é educador, ou se é linguista), ao contrário da França, onde as regiões de pesquisa são bem menos limítrofes, ou mais esponjosas que as muralhas por vezes intransponíveis das áreas e sub áreas científicas brasileiras.

Fica por se explorar no Brasil, como afirma Soares (2003, p. 20-21), estudos em que de fato certos autores de renome mundial da Linguística, como Ferdinand Saussure 7 , Émile Benveniste, Oswald Ducrot, Marion Carel e Michel Pechêux ${ }^{8}$, dentre tantos outros, sejam tomados não por colaboração, mas pela suas pertinências reflexivas e metodológicas para se analisar os processos de aprendizagem de linguagem. Dito de outro modo: são tênues e quase nulos trabalhos em que a teoria destes autores consagrados acima podem ser (re)visitadas enquanto verdadeiros gestos, métodos, procedimentos de ensino/aprendizagem, para o ensino fundamental e médio, por exemplo, e não só contribuintes ou indicadores de nortes.

\footnotetext{
${ }^{6}$ Como, por exemplo, os excelentes trabalhos de Luiz Carlos Cagliari.

${ }^{7}$ Evidentemente, há, no Brasil, estudos que aplicam a teoria saussuriana ao o ensino. É exemplo disso o excelente trabalho de Xavier (2014). Contudo, ainda se carece, no Brasil, de aprofundamentos de análises de procedimentos para o ensino de línguas, e de maturidade de profundidade para com as obras póstumas de Saussure (os Écrits e o Cours), com vistas a esse fim do ensino de língua portuguesa e com vistas à exploração das ditocomias em aulas de línguas. Alvos desta pesquisa.

${ }^{8}$ Embora já existam iniciativas felizes e interessantes entre Educação - Linguística, que leve em conta alguns destes autores, sobretudo: Michel Foucault, Mikail Bakhtin, e alguns de Michel Pêcheux.
} 
Mais que apontar nortes, estes autores poderiam proporcionar verdadeiros métodos de ensino, e não apenas sinalizar concepções de linguagem. Isto sim, seria um exemplo de ciência interconstitutiva entre saberes, longe da menção resenhosa e estanque da "contribuição".

É nesta lacuna interdisciplinar que este artigo soergue-se. Propomos, aqui, um procedimento científico talvez contrário ao tradicional: (re)pensar a Linguística pela Educação (ou vice-versa), como recomenda Cagliari (1996, p. 30): "quem lida com o ensino de linguagem tem que saber Linguística". E saber não é citar. Saber não é resumir certa teoria introdutoriamente com fim ratificador. Para Cagliari, saber, em ciência, é poder apropriar-se para efetivar análises. É neste imbricamento que, concretamente, tais autores de respeito mundial nas Ciências da Linguagem precisam ser tomados in praesentia, não como colaboradores, mas como propositores de verdadeiros processos de ensino.

Para proceder contrariamente a esta lacuna, propósito-mor deste trabalho, valer-nos-emos nada menos que do conceituado fundador da Linguística moderna: Ferdinand de Saussure. Nosso objeto de estudo, então, é duplo: o processo de aprendizagem da linguagem, por um lado, e as obras póstumas de Saussure: (1) Cours de Linguistique Générale ${ }^{9}$ e (2) Écrits de Linguistique Générale, por outro.

A primeira (1) raramente trabalhada na Educação sem auxílio de apud, e reduzida a uma leitura fragmentada do "signo linguístico"; e a segunda (2), inexistente em publicações brasileiras sobre Ensino, e por isso desconhecida dos pedagogos brasileiros. Deste modo, nosso trabalho ganha o caráter de pesquisa bibliográfica inédita.

Estaremos então filiando este artigo na Educação ou na Linguística? Esta pergunta só desconstrói nosso objeto de estudo, porque, no contexto internacional em que este trabalho foi pensado, é fato que a França não delimita seus saberes de modo tão estanques como o Brasil (até aqui é

\footnotetext{
9 Seguindo uma tradição de linguistas exigentes, preferimos fazer uso do original (em francês), colocando em segurança o conteúdo da obra ao evitar erros voluntários ou não que toda tradução ameaça carregar.
} 
Sociologia, até ali é Linguística, se passar daqui já não é Política etc.). Ademais, "forçar filiações" pode produzir o gesto de perpetuar a direção unilateral que queremos desconstruir. Se a filiação epistemológica (aquela que "enquadra" cada estudo em cada teoria) é necessária para fins organizacionais, não necessariamente é pertinente para fins científicos. Indaguemo-nos: e se descobrirmos, quiçá futuramente, novas áreas, ao aceitarmos novos contratos e novos agrupamentos? E se desfizermos convenções antigas, e aceitarmos empréstimos e mobilizações limítrofes e oscilantes entre áreas? Sobre esta hipótese, nos ensinou brilhantemente o Mestre Saussure (2002, p. 262)10, já no início do século:

Nós discutimos para saber se a Linguística pertence à ordem das ciências naturais ou às ciências históricas. Ela não pertence a nenhum dos dois, mas a um compartimento das ciências que, se ele não existe, deveria existir sobre o nome de Semiologia, que significa ciência dos signos ou estudo daquilo que se produz quando o homem tenta significar seu pensamento pelo meio de uma convenção necessária.

Neste trecho ousado, além de desfiliar a Linguística das áreas tradicionais, Saussure acaba apresentando sua original definição de linguagem. Saussure se fasta da técnica: se toca a mente é Psicolinguística, se toca a variação de línguas é Sociolinguística, se toca a norma é Gramática etc.

Segundo seu raciocínio de evitar filiações, refletiremos a linguagem saussurianamente, valendo-se dos originais do autor. Diremos, na melhor das hipóteses, que nosso artigo imbrica o espaço de alfabetização francês e brasileiro, com foco no fenômeno educacional da linguagem por vias teóricas de Ferdinand Saussure, construindo procedimentos para o ensino de língua

\footnotetext{
${ }^{10}$ Do original: «On a discuté pour savoir si la linguistique appartenait à l'ordre des sciences naturelles ou des sciences historiques. Elle n'appartient pas à aucun des deux, mais à un compartiment des sciences qui, s'il n'existe pas, devrait exister sous le nom de Sémiologie, c'est-à-dire sciences des signes ou étude de ce qui se produit lorsque l'homme essaie de signifier sa pensée au moyen d'une convention nécessaire » (SAUSSURE, 2002, p. 262).
} 
portuguesa. Trabalho sem precedentes, se tomado enquanto procedimento para aquisição / aprendizagem / funcionamento da linguagem.

\section{Ferdinand Saussure}

Ferdinand Saussure é conhecido nos manuais de Linguística como "o pai da Linguística moderna”. E seu epíteto não é exagerado. Foram seus estudos a fonte do Estruturalismo europeu, e depois mundial, que tanto fez progressos científicos na maioria do rol de saberes mundo afora: Psicanálise, Filosofia, Artes, Linguística etc.... Esboçar a riqueza de suas percepções neste espaço seria impossível, e reclamaria o portento de um artigo só para este fim. Existe, para isso, vasta publicação de peso sobre este autor e sua riqueza de concepção (e raras pesquisas quanto à sua apropriação efetiva para a Educação).

Os estudos de Saussure inauguram um novo eixo para se pensar a linguagem: as dicotomias, de pertinência gigantesca para a(s) ciência(s) do século XX e XXI. Eixo este que queremos recuperar especificamente no ensino de português do Brasil, ao (des)(re)construir o modo de se usar Saussure no Ensino de língua portuguesa brasileiro (apenas como realce). Este artigo visa refletir a concepção de linguagem saussuriana na sala de aula para além do modo como Saussure é traduzido em materiais didáticos: resumindo suas dicotomias vagamente, ou recortando exemplos isolados e sem interação com a prática do ensino, e apenas rascunhando curtas análises em segundo plano sem as protagonizar em atividades principais.

\section{As dicotomias saussurianas}

Saussure inaugurou, no campo das ciências humanas, a língua enquanto objeto científico de estudo (nunca antes tida como tal). Soma-se a esse refinamento o fato do patriarca da linguística ser professor em 
Genebra: ser professor e linguista particulariza sua teoria na seguinte direção: o ensino de linguagem. Tão caro à alfabetização.

Saussure nunca publicou, mas escrevia intensamente ${ }^{11}$. Sua escrita é tão profícua que se encontrou análises em guardanapos e folhas de qualquer natureza. De fato, podemos condensar o cerne dos trabalhos deste gênio da linguagem nas condensações de suas dicotomias. As dicotomias saussurianas, modos de se pensar a linguagem e seu funcionamento por pares de procedimentos, foram publicadas em seu livro póstumo, editado por seus alunos Charles Bally e Albert Sechehaye, a partir de notas de seus alunos por ocasião de três cursos ministrados na Université de Genève, de 1907 a 1911. Daí em diante, metaforicamente percebendo, "uma luz acendeu-se nos estudos sobre linguagem" - antes apenas comparativos e estilísticos -, de modo que os estudos saussurianos nunca mais foram deixados de lado, e no desenrolar das ciências de linguagem, são (re)tomados mundialmente e constantemente. As quatro dicotomias saussurianas clássicas são:

a) significante / significado

b) fonação / audição

c) fala / língua

d) Sintagma / Paradigma

Para este artigo de cunho introdutório, que condensa reflexões em dois países distintos nos últimos 10 anos, a reflexão basal é iniciar uma formalização de procedimentos saussurianos para o ensino de língua portuguesa no Brasil, e para tal, escolheremos, enquanto objetivo específico, eleger a dicotomia significante / significado, que corresponderá a procedimentos básicos para o processo de ensino/aprendizagem de linguagem:

A hipótese deste artigo é direta, e nada transversal: na concepção em que se soergue esta pesquisa, as dicotomias não serão meramente modos de se compreender a linguagem humana, mas serão, a priori, procedimentos

\footnotetext{
${ }^{11}$ Saussure produzia continuamente. Mas a totalidade de sua reflexão são anotações, pois nunca publicou um livro. É recomendável, para os pedagogos que queiram se aprofundar nos procedimentos saussurianos, a leitura do recém descoberto Écrits de Linguistique Générale (SAUSSURE, 2002), tardiamente chegado ao Brasil.
} 
para o ensino de língua materna para alunos do ensino fundamental e médio do Brasil. Por isso não falaremos em dicotomia, mas procedimento dicotômico. Dicotomia é uma percepção de linguagem, e procedimento dicotômico é um gesto com fim específico, aqui, o de ensino/aprendizagem da linguagem. O procedimento dicotômico será, aqui, modos de apropriação e uso de linguagem (que apresenta plena harmonia com a noção de letramento ${ }^{12}$, como veremos). Todo par dicotômico é, aqui, um gesto procedimental, e não apenas uma consideração abstrata.

Só esta mudança de acepção teórica nos abre um leque inteiro a se pensar, e todo um acarretamento procedimental a se construir. Um leque que ainda está por ser escrito, e que apenas iniciaremos de modo introdutório nos próximos tópicos.

Neste contexto, a metodologia eleita para este artigo consistirá em um procedimento duplo de: (a) apresentar a explicação do que são cada um dos procedimentos dicotômicos ao (b) aplicá-los em vários corpus de situações didáticas do ensino de língua portuguesa, escolhidos pela sua ilustratividade concernente à proposta do procedimento dicotômico. E se a nossa postura analítica é propor a formalização de procedimentos pedagógicos, tanto (a) como (b) só serão perceptíveis em concomitância, no seu duplofuncionamento.

Isto nos exime do trabalho de explicar isoladamente, por ora, o que são cada um dos procedimentos dicotômicos acima (gesto a), e nos sugere o procedimento analítico de seguir à análise de corpus (gesto b) para efetivar a nossa hipótese da proposta saussuriana para processos de letramentos.

\section{O procedimento dicotômico "significante / significado": o signo}

\footnotetext{
12 Adotaremos, para fins desta pesquisa, a definição de letramento de Soares (2002, p. 145), sem adentrar na riqueza de suas discussões e polêmicas: letramento é "o estado ou condição de quem exerce as práticas sociais de leitura e de escrita, de quem participa de eventos em que a escrita é parte integrante da interação entre pessoas e do processo de interpretação dessa interação - os eventos de letramento".
} 
O signo linguístico, nome que Saussure deu à indesviável soma \{significante + significado\}, diz respeito à natureza da linguagem de (sempre) relacionar uma espessura acústica da língua (um som, chamado de fone, alofone, fonema, ruído etc.) a uma imediata imagem mental, um conceito. Assim, a todo som de linguagem (imagem acústica) corresponde um conceito (imagem na mente). Como ensina o mestre: "nós chamaremos signo à combinação entre o conceito e a imagem acústica" (SAUSSURE, 1985, p. 99) ${ }^{13}$. Deste modo, fica estabelecido que a constitutividade da linguagem é vislumbrada, na essência, pelo signo, que é a união entre som + imagem mental\}. Dito de outro modo, \{significante + significado\}, respectivamente.

Já temos uma premissa para a grande área do Ensino: valer-se da teoria saussuriana significa concordar que aprender uma língua é aprender signos (e não repetir mecanicamente letras, sílabas ou palavras, pois a repetição de som é apenas "metade" do signo). Aprender signos nas aulas de língua materna (ou não) é/será estabelecer estratégias entre sons (o significante) e as imagens correspondentes a estes sons (os significados). Toda atividade e método, por mais variados e distintamente objetivados, fundamentar-se-ão nessa premissa da aquisição de signos.

A teoria de Saussure é extremamente clara neste ponto, e outras interpretações empobrecidas, como dizer que estudos mecânicos de relacionar palavras a coisas, para decorar ortografias constituem a essência de um estruturalismo saussuriano, não têm respaldo bibliográfico, já que o mestre é claro: "o signo linguístico une não uma coisa e um nome, mas uma coisa e uma imagem acústica" (SAUSSURE, 1985, p. 98).14 Ou: [...] "as 'coisas' das quais falamos aqui são signos" (SAUSSURE, 2002, p. 263) ${ }^{15}$.

O professor deve cuidar-se para a contraparte de que exercícios sonoros, vazios de significado, isento de semantismos, e vice-versa, estudos de avalanches de semantismos, deografias ou ícones, isentos da enunciação

13 Do original: «Nous appelons signe la combinaison du concept et de l'image acoustique » (SAUSSURE, 1985, p. 99).

${ }^{14}$ Do original: «Le signe linguistique unit non une chose et un nom, mais un concept et une image acoustique $»$ (SAUSSURE, 1985, p. 98).

${ }^{15}[\ldots]$ « Des < choses > dont on parle ici sont des signes » (SAUSSURE, 2002, p. 263). 
dessas ideias ou semantismos, não vingam pela ótica saussuriana, cujo refinamento exige um aprendizado de linguagem que construa e faça funcionar signos. Tomemos o exemplo de signo do próprio Saussure:

FIGURA 1: o signo de Saussure

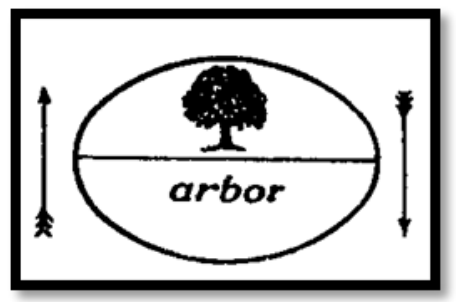

Fonte: Saussure (1985, p. 99)

Sigamos as divisões propostas por Ferreiro e Teberosky (1985). O aluno que está em processo de aprendizagem pré-silábica, silábica, silábicoalfabética ou alfabética, por ocasião do aprendizado da palavra “árvore", construirá mentalmente o seguinte signo, mais ou menos da seguinte forma (já que é complexo desenhar o processo de aquisição da linguagem): som [a.vori] e imagem mental [. Desta momento em diante, a enunciação de "árvore" acarretará o signo: $\left\{\left[\right.\right.$ aıvori] ${ }^{16}+[\}$, pois não se separa som (significante) do conceito mental (significado): "Nós proporemos conservar a palavra signo para designar o total, e de substituir conceito e imagem acústica respectivamente por significado e significante (SAUSSURE, 1985, p. 99) ${ }^{17}$.

\section{Primeiras análises do procedimento dicotômico do signo}

Passamos a um gesto de aplicação teórica à dimensão processual da aprendizagem de língua materna. Se para Saussure, estudar e aprender a linguagem não significa relacionar "uma palavra a uma coisa no mundo",

\footnotetext{
16 [a.vori] = transcrição fonética de uma execução da palavra "árvore", conforme notação do IPA - International Phonetic Alphabet. Todas as ocorrências de transcrições fonéticas desse trabalho valer-se-ão desta notação.

${ }^{17}$ Do original : « Nous proposons de conserver le mot signe pour désigner le total, et de remplacer concept et image acoustique respectivement par signifié et signifiant».
} 
como defendia Frege, mas significa relacionar "um som a uma imagem na mente”, isto significa que um ensino de línguas não se pauta, para Saussure, na relação direta entre o mundo (objetos físicos) e a linguagem (palavras, expressões, preposições etc.): identificar letras alfabéticas substantivos, concretos ou abstratos. O ensino de linguagem, para Saussure, se perfaz na praxe social que produzirá relações entre sons e imagens destes sons. O que não significa que não exista o mundo, físico concreto e palpável, muito ao contrário: significa que é a linguagem que cria "mundos possíveis", além do físico, concreto e palpável. O professor de língua materna leva a responsabilidade de ensinar arquitetura de mundos, cujos instrumentos são as linguagens.

O professor não ensina a relação entre a palavra "banco" e o prédio físico situado em um logradouro. O professor faz a intermediação na criação da relação som-significante $[\mathrm{bãk} U]^{18}$ e imagem-significado [ $[\underline{\underline{\underline{\underline{\underline{I I}}}}}]^{19}$, formando

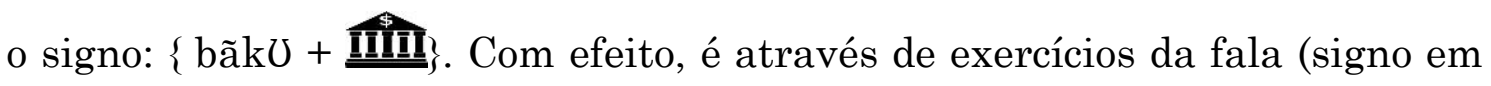
uso) que se poderá significar argumentativamente 20 "banco - exploração": $\{$ esplorasãw $+\underline{\underline{\underline{\underline{\underline{I I}}}}}\}$, ou "banco - poupança": \{popãsə $+\underline{\underline{\underline{\underline{\underline{I I}}}}}\}$.

Geralmente, por uma tradição de classe média e alta, freia-se o ensino apenas no banco-poupança. São raros os materiais didáticos de língua portuguesa que exploram a argumentação \{banco - exploração\}. Ducrot (2005, p. 107-108) categoriza os semantismos da língua em positivos (significações preferíveis no senso comum, por exemplo: ser "prudente" é positivo) e negativos (significações menos preferíveis no senso comum, por exemplo, "prudente demais" é negativo). É fácil concluir que o ensino de língua portuguesa, no Brasil, faz protagonizar semantismos e discursos positivos (por exemplo, "banco-poupança"), evitando semantismos negativos (por exemplo, "banco-exploração"). A questão que se põe aqui no ensino de

\footnotetext{
18 [bãkひ] - transcrição fonética da palavra "banco".

19 Imagem disponível em <https://docplayer.com.br/50778934-Plano-de-estudo-teste-02-ciencias-8o-ano-2otrimestre.html>. Acesso em 19 março 2020.

${ }^{20}$ Conforme estudos argumentativos de Carel (2011), por exemplo. Excelente recomendação para o pedagogo que busca extrapolar/ampliar a visão da significação dos signos.
} 
língua materna (que anda junto e não escapa do ensino de semântica) não é evitar sentidos ruins e "ensinar sentidos bons", mas é, à luz de Saussure, reconhecer os dois signos: "exploração" e "poupança”, pois aprender uma língua é saber que a aprendizagem do arquivo de linguagem vem primeiro, o julgamento e escolha desse arquivo, vem depois, e extrapolando as aulas de língua portuguesa.

\section{Uma análise da construção do signo "acreditar" em aulas de língua portuguesa}

Outro desdobramento da aplicação da teoria saussuriana ao ensino. $\mathrm{O}$ pressuposto do signo pode ser interessante e produtivo para trabalhar, inclusive, a aquisição de substantivos abstratos em sala de aula. Pensemos como seria / construir-se-ia os signos "acreditar" e "poder", no ensino de português brasileiro. Tal como no signo dos substantivos concretos, como "árvore", verbos e substantivos abstratos também mobilizarão uma relação entre som e conceito. A questão talvez tornar-se-á complexa por ocasião da elaboração de um conceito mental para os sons [akred3itax] e [podeı] ${ }^{21}$.

O professor, valendo-se da percepção social que funda a linguagem, deverá apresentar "significados" concernentes às ideias de crença, enquanto enuncia, no interior de vários contextos, o "significante" [akred3itai]. Os significados podem ser, por exemplo: religiosos (acreditar em Deus), afetivos (acreditar na família), amistosos (acreditar nos amigos), sociais (acreditar na política), humanitários (acreditar nos filantropos), de autoestima (acreditar em si mesmo), dentre outros, para que o estudante mobilize um signo (significante + significado) perspicaz e eficiente dessa ideia e com pertinências sociais, afastando-se do ensino de signos exageradamente ingênuos, como um simples: "acredito em papai Noel” ou "acredito na paz", o primeiro mítico e não produtivo socialmente (o papai Noel), o segundo utópico e ingênuo (a paz enquanto conceito purista, e como ausência de

\footnotetext{
${ }^{21}$ [akred3itaı ] e [pode.I] - transcrição fonética das palavras, respectivamente, "acreditar" e "poder".
} 
guerra), e ambas isolados de uma pertinência social, alheios a práticas de letramentos.

É produtivo que o pedagogo desprefira o signo mítico da paz "passiva" em detrimento de atividades letradas que construam o signo de uma paz "ativa". Isto é, as atividades de letramento pertinentes socialmente e estratégicas nessa aula temático-semântica é a construção do seguinte signo: é possível haver paz em meio a um mundo caótico e injusto? Se sim, deve-se encontrá-la ou construí-la? E construir essa "paz militante” como? Como elaborar esses significados? Um início produtivo pode ser a apreciação de textos biográficos de militantes da paz, que deixam como legado verdadeiros savoir-faire de letramentos em prol da paz, como o gesto de "paz corajosa", de Heley Batista ${ }^{22}$; a luta constante pela "paz para as minorias", de Marielle Franco; e a constante e necessária "paz político-diplomática”, de Aracy Rosa ${ }^{23}$; dentre outros(as).

O signo é o primeiro "dicionário cerebral" da linguagem. É interessante, por isso, que o professor provoque a investigação de um único signo linguístico para toda a turma. Quanto mais dificuldade em elaborar um significado para o significante [akred3itar], mais exposições de situações críveis devem se apresentar. As associações linguístico-cerebrais constroemse via exposições de mundos possíveis, isto é, através da exposição de complexos de mundo. E não forjando um mundo não complexo, ou "escondendo" realidades complexas do mundo ou sentidos "negativos", em aula de português. Na esteira de Benveniste (1968), devemos ser radicais: não lemos frases, lemos culturas. Assim, aprender uma língua é aprender uma cultura. De modo que o pedagogo deve ter em conta que, pela postura saussuriana, não se ensina definição de palavras alheias ao mundo, ensina-

\footnotetext{
${ }^{22}$ Em 2017, a cidade de Janaúba-MG ficou famosa por um incêndio em uma creche, resultando em 14 mortos, provocado por um vigilante local. Heley, professora da creche, corajosamente abraçou o criminoso para impedir o ataque, e auxiliou no regaste das crianças feridas. Ela ficou com $90 \%$ do corpo queimado, e infelizmente não resistiu aos ferimentos.

23 Aracy, poliglota natural de Rio Negro-PR, trabalhou no consulado brasileiro em Hamburgo, na seção de passaportes. Fez com que judeus conseguissem fugir do nazismo e entrassem no Brasil, emitindo vistos considerados ilegais. Ficou conhecida como "Anjo de Hamburgo" e foi reconhecida com o título "Justa Entre as Nações". É a única mulher citada no Museu do Holocausto de Jerusalém, dentre 18 diplomatas que arriscaram suas vidas para salvar judeus do Holocausto.
} 
se funcionamentos sociais e, a partir daí, deflagram-se definições. Na esteira de Benveniste (2006, p. 97), o professor da aula de língua portuguesa precisa levar em conta duas proposições bases:

Estamos considerando aqui a língua somente como meio de análise da sociedade. Para este fim tomaremos língua e sociedade em sincronia e numa relação semiológica: a relação do interpretante com o interpretado. E formularemos essas duas proposições: em primeiro lugar, a língua é o interpretante da sociedade; em segundo lugar, a língua contém a sociedade.

Ensinar linguagem é tomar a aula de português como espaço de reflexão pragmática e social, via linguagem, com toda complexidade que lhe constitui, e não espaço de silenciamento de conceitos (o que subverteria uma sociedade, que não existe sem problemáticas e falhas).

Sobre o signo "acreditar", perguntas diretivas podem integrar os procedimentos de letramento. Primeiro, perscrutar a sociedade: "em quem vocês acreditam?" e depois definir conceitos da sociedade: "então o que é acreditar?". Deste modo, o professor pode construir um mural de signos. Um mural de termos mais eruditos, abstratos, de dificuldade imagética maior (isto é, inclusive, um pequeno curso de formação de linguagem erudita, para ler Shakspeare ou Machado de Assis futuramente, por exemplo).

\section{Uma análise da construção do signo "poder" em aulas de língua portuguesa}

Como trabalhar, por outro lado, a palavra "poder"? Mais uma vez o pedagogo saussuriano se vê cercado de um mar criativo de funcionamentos sociais, em que o poder se manifesta de forma plural, heterogênea, e imprevisível, e deve ser levado em conta para o aprendizado desses signos, em ensino de línguas. O complexo social de formatos de poder (político, sedutor, familiar, influenciador, "poder passivo" etc..), que pressupõe o eixo 
semântico "poder portanto poder fazer alguma coisa com algo ou alguém"24, deve chegar ao estudante, em aulas de construção do signo, para só depois pedagogicamente auxiliar a elaboração mais universal de signos desse conceito-som, o "poder". O professor de línguas deve ter em conta a máxima saussuriana e benvenistiana de que não se separa língua e sociedade, isto é, pedagogicamente, não vinga (ou é deveras fragmentado). Por exemplo, tal como defendem os pesquisadores do ensino de língua estrangeira (LE), gramatizalizar ("ensinar") uma língua (o inglês, por exemplo) e depois enviar o aluno para o espaço social dessa língua (os Estados Unidos, por exemplo), é prática que tem sempre fracassado, dado o precipício causado por este processo entre o social-excluído e a norma-vazia.

Exemplifiquemos. Fábulas como "o leão e o rato", por exemplo, cumprem bem o papel de fornecer conceitos-significados ao som-significante [podex]: o leão tem o poder físico (signo adjetivado: poder físico), e o rato tem um poder inteligente (signo adjetivado: poder intelectual). O signo "poder" é um bom exemplo de palavras que possibilitam, ao pedagogo saussuriano, adjetivar signos (ampliar conceitos, complexizar dinâmicas, relativizar estereótipos). Desdobrar signos é uma estratégia criativa que o procedimento dicotômico significante/significado.

A atividade de aula pode prosseguir, pelo método filosófico indagativo: “quais poderes observamos na sociedade?" O aluno apreenderá, ainda em fase alfabética ou silábico-alfabética, o que Foucault (2009) trabalhou no ensino superior da França: os micropoderes que extrapolam estruturas visíveis e rígidas. Os micropoderes (desdobramentos do signo "poder") estão narrados à exaustão nos muitos livros de contos de fadas e fábulas ${ }^{25}$, por exemplo:

\footnotetext{
${ }^{24}$ Vamos adotar aqui, para análise semântico-fonêmica das espessuras significantes e significadas dos signos que iremos operar, a noção de aspect argumentatif (aspecto argumentativo), desenvolvida pela renomada linguista francesa Marion Carel (2011). Trata-se de ligar dois constituintes semânticos pelo conectivo portanto, e no entanto. Por exemplo:

Signo "prudente" - [há certo perigo portanto evitar];

Signo "aprovação escolar": [conhecimentos construídos/apresentados portanto averiguar evolução ou não desses conhecimentos].

${ }^{25}$ Ver, por exemplo, nossos trabalhos em Machado (2017).
} 
$\checkmark$ o significante sonoro [pode. da belezə] ${ }^{26}$ pode ser ilustrado pelos significados das imagens de bruxas dos contos de fadas que se fazem de princesas belas;

$\checkmark$ o significante [pode. da spe.tezə] ${ }^{27}$ pode ser associado ao significado do "Gato de Botas", cuja atuação de poder enriquece;

$\checkmark$ o significante [pode. da ĩteli3ẽsiə] ${ }^{28}$ pode associar-se ao significado imagético do poder que salva, em "O pequeno Polegar", dentre outros.

Os contos de fadas ou fantásticos, que para o pedagogo não é entretenimento, mas verdadeiro vislumbre dos funcionamentos sociais, são por isso instrumentos pedagógicos eficazes no processo de aquisição de signos em aulas de português, uma vez que os contos de fadas ilustram, nos signos que carregam, exemplificações vivas dos micropoderes sociais, se lidos semântico e socialmente, e não por entretenimento.

Saussure (2002, p. 263) explica: "todo fato linguístico consiste em uma relação, e não consiste em nenhuma outra coisa a não ser a relação" 29 . De modo que a pertinência procedimental do signo para a alfabetização e os letramentos é tal que, ao estudar um signo, imediatamente é-se levado a estudar outros signos, pelos desdobramentos de valores que acarretam. Por exemplo, ao caracterizar o signo "poder" por "poder da beleza", entramos no trabalho do signo "sedução"; ao caracterizá-lo por "poder da esperteza", trabalhamos o signo "oportunista" ou "oratória"; igualmente, ao caracterizar o signo "poder" por "poder da inteligência", é-se conduzido a signos do empreendedorismo, de gestão, como: "pró-ativo", "atitude”, “criatividade” e "poder de venda".

Dado que "as práticas de letramento explicitam diferentes estados de apropriação dos usos da língua por diferentes grupos sociais" (BELMIRO, 2003, p. 307), um grupo social de forte interesse escolar é inegavelmente (as

\footnotetext{
${ }^{26}$ [pode. da belezo] = representação fonética de "poder da beleza.

${ }^{27}$ [pode. da spertezə] = representação fonética de "poder da esperteza".

28 [podeı da îtelizẽsia] = representação fonética de "poder da inteligência".

29 Do original: «tout fait linguistique consiste en un rappport, et consiste en rien d'autre qu'en un rapport» (SAUSSURE, 2002, p. 263).
} 
exigências do) o capitalismo. Escolas mais afinadas pelo diapasão das exigências hodiernas do capitalismo (escolas de formações gerenciais, por exemplo) trabalham, inclusive, posturas de economia criativa ${ }^{30}$, valendo-se, para otimizar o poder do convencimento (de compra e venda), da exploração dos "poderes sociais" nas faces incontáveis dos mercados diversificados, tendências modernas de mercado, globalização, mídias digitais e vantagens competitivas, com vistas a potencializar a economia do país e contribuir para o desenvolvimento da nação, à luz da identidade cultural desse país ${ }^{31}$. Neste contexto, dado o papel escolar de perpetuação e manutenção capitalista, que transforma a frase "o que você será quando crescer?" em “como você ganhará dinheiro?", aprender uma língua, em escolas brasileiras, adquire um status de "valer-se da linguagem para condições empregatícias", letramentos capitalistas, e trabalhar o letramento de signos como: oportunidade, felicidade, criatividade e uso do tempo, por exemplo, culminarão em aprendizagem linguística para práticas sociais de mercado (o que ocorre quase que involuntariamente): [opostunidaddzi portanto avanço social], [felisidadzi portanto alguém bem-sucedido no emprego], [kriatividadzi portanto sucesso profissional] e [uzU du têpひ portanto multiplicar dinheiro] (time is Money).

Pois o método do signo instaura a observação da diferença, amplia o vocabulário do estudante porque amplia relações, como resume radicalmente Saussure (2002, p. 263): "todo fato linguístico consiste em uma relação, e não consiste em nenhuma outra coisa a não ser a relação" 32 . Deste modo, o signo, tomado enquanto procedimento de aprendizagem, é o método da relação, é a suma de que um signo ensinado revela uma rede de signos aprendidos e apreendidos, porque relacionados. A cognição da linguagem,

\footnotetext{
${ }^{30}$ O conceito de Economia Criativa, de grande consideração hodierna, nasceu na Austrália, em 1994, em um discurso intitulado "Creative Nation", onde Primeiro-Ministro australiano Paul Keating afirmou: "The level of our creativity substantially determines our ability to adapt to new economic imperatives. It is a valuable export in itself and an essential accompaniment to the export of other commodities. It attracts tourists and students. It is essential to our economic success."

${ }^{31}$ A esse respeito, ler, dentre outros, Serra e Fernandez (2014).

32 Do original: «tout fait linguistique consiste en un rappport, et consiste en rien d'autre qu'en un rapport» (SAUSSURE, 2002, p. 263).
} 
tomada seja por qual for o viés de vislumbramento científico, faz funcionar a linguagem por relação. E o signo é, neste processo, procedimento adequado para aprendizagem de linguagem.

O resultado de uma pedagogia saussuriana é um aluno que capaz de ler a sociedade, porque letrou-se no conceito de que "a língua interpreta a sociedade” (BENVENISTE, 2006, p. 98), capaz de ler-apropriar-se, por isso, da língua na sua inter-relação com o complexo de mundo, não uma língua ingênua, construída a base de regras verificáveis e corrigíveis, mas uma língua indissociável do social, que leva às práticas do mundo e constrói mundos, baseado em signos.

\section{O "bom aluno" e o signo saussuriano}

Cremos que a Educação tem muito a aprender com Saussure, se redescobrir Saussure (e pelo verbo "redescobrir", neste artigo, entende-se reler os originais, o "Cours" e os "Écrits", o primeiro de tradição apenas de menção e exemplificação, o segundo raramente ou sequer veiculados na área do saber de Ensino, no Brasil. Até o presente momento de nossa pesquisa, cujo escopo de reflexão encontra-se neste artigo, faz ver que o estudo aprofundado do signo nas aulas de língua portuguesa, no Brasil, leva a perceber que a dicotomia significante-significado, que constitui a linguagem, é um verdadeiro pivô metodológico para as aulas de língua portuguesa, e este estudo têm mostrado que aprender uma língua (aprender signos) acaba por tocar a grande área dos processos de leitura. Isto é, os vários modos de apreensão e leitura de signos organizarão, em pesquisas futuras, tipos de alunos-leitores, tal como concluir inicialmente abaixo, a partir de um curto exemplo:

$$
\text { “João é um bom aluno". }
$$


Como construir "significado" para o "significante" [bõ'alũno] ${ }^{33}$, em aulas de português, no Brasil? Esse artigo mostrou que as leituras possíveis, à luz da dicotomia saussuriana do signo, desdobram-se, já que signo é relação. Esses desdobramentos de leitura de signos podem ser categorizados pelo menos em:

$\checkmark$ leitor da decodificação de signos (identificação criativa e ampliativa do vocabulário de signos):

[bõ alũnu portanto tirar boas notas];

[bõ alũnซ portanto apresentar discursos autorais];

[bõ alũn portanto saber ser sociável com os colegas] etc.;

leitor da função dos gêneros sígnicos (percepção estratégica das funções de grupos de signos):

[bõ alũnช portanto obter favores dos professores];

[bõ alũno portanto ser endossado para empregos];

[bõ alũno portanto influenciar profissionais da escola] etc.;

$\checkmark$ leitor da argumentação dos signos (leituras interdependentes de pares de signos): bõ alũnv - [há ações a se executar portanto executar tais ações com excelência];

bõ alũno - [há desafios no entanto não desiste];

bõ alũno - [compreender o que o professor quer portanto fazer o que o professor quer] etc..

$\checkmark$ leitor da evasão pelos signos (apreensão dos signos para entretenimento, a que se estimula no Brasil e países sem leitores (ABREU, 2001, p. 150):

[bõ alũno portanto ler livros enquanto entretenimento];

\footnotetext{
33 [bõ‘alũnv] = transcrição fonética de uma execução da palavra "bom aluno", conforme notação do IPA International Phonetic Alphabet.
} 
[bõ alũnu portanto ler livros "não clássicos" ou "desconsiderados pelo rol das escolas"];

[bõ alũno portanto ler em tempo livre] etc.;

leitor da formação pelos signos (utilização dos signos para conhecimento escolar, profissional, acadêmico etc.):

[bõ alũno portanto proceder a leituras técnicas, teóricas, ou formativas];

[bõ alũnv portanto ter domínio técnico de certo saber];

[bõ alũno portanto ser capaz de citar autores de renome] etc..

Deixa-se, para efeito de fim, uma provocação: se “[...] grande parte dos brasileiros não têm efetivamente condições sociais de ser leitores" (ABREU, 2001, P. 154), fica a pergunta, provocativa e por isso produtiva: qual destas leituras (e como) o pedagogo brasileiro tem trabalhado nas escolas em que atua?

\section{Conclusão}

Vimos que a noção de língua e fala de Saussure corrobora com o que Cagliari (s/d, p. 72) conclui: "A escola tira o ambiente natural de uso da linguagem e o coloca em um contexto artificial”. Ali, privilegia-se o falar "sobre" a língua, e não "a" língua, que a dicotomia saussuriana desconstrói, em prol de uma aprendizagem completa da competência linguística.

Podemos estar diante de um outro modo de se pensar o ensino de linguagem. Evidentemente que os bons leitores de Saussure dirão que muito se deixou de lado neste artigo, o que concordamos, dado que a riqueza saussuriana é tão vasta, e tem tamanho impacto na ciência mundial, que a sua parca reflexão em apenas uma face, a do ensino, é deveras insuficiente e introdutória, ainda. Abordamos, aqui, apenas a dicotomia do significante / significado para refletir sua aplicabilidade à grande área da Educação, 
enquanto procedimentos para o ensino, e ainda em tom bibliográfico-teórico, e introduzir a teoria saussuriana ao pedagogo/pesquisador do ensino de línguas, no Brasil, teoria bem distante das salas de aulas.

É raro, no Brasil, publicações em que de fato Saussure é tomado na sua riqueza e profundidade teórica para a aquisição da linguagem. Saussure não pode se resumir em distinções ortográficas (cata, cada, cala etc..). Os originais Cours de Linguistique Générale e Écrits de Linguistique Générale nos convida a uma releitura de toda a contribuição saussuriana e a consequente atualização de como a teoria saussuriana era pensada. Este artigo quis mostrar que Saussure funda uma escola de linguagem (não só significante, mas significada). Este é o principal mérito de se (re)descobrir Saussure, aprendendo com seus novos escritos, ampliativos e macroprocedimentais, repensando re-leituras tradicionais, delimitativas e micro-operacionais. Aulas de português precisam dinamicizar discursos de toda ordem, por isso deve saber lidar com a construção, transmissão e transformação de signos de várias esferas sociais, e para isso, precisa de instrumentos eficazes nessa direção.

Concluamos esta pesquisa, enfim, de modo mais epistemológico: este artigo introdutório reclama, por fim, direções de aprofundamentos mais específicos para a dicotomia aqui apresentada - e das não apresentadas por um panorama mais geral. Se Saussure é chamado pejorativamente de estruturalista, na falta de leituras menos superficiais e por isso menos preconceituosas sobre o estruturalismo, diremos que é imperativo, no Brasil, redescubra-se o (que se pensava ser) Estruturalismo ${ }^{34}$ : não uma ciência pobre e limitada, mas uma ciência cujo sistema estrutural é de base dinâmica e de semantismo inesgotável, quando se confronta língua e fala. Essa seria uma definição mais justa do estruturalismo, para os experts. O que todo estruturalismo faz é explicitar quão rica e ilimitada é o sistema

\footnotetext{
${ }^{34}$ Nesta linha de releituras mais inteligentes, mais fiéis aos originais e menos ingênuas ou superficiais, sugerimos as excelentes leituras críticas de Simon Bouquet (2012), por exemplo.
} 
tornado paradoxal, "vertebrado-invertebrado", pela essência semântica inerente ao fenômeno da linguagem.

Para fazer ecoar (e se responder) ainda mais esta provocação, findamos esta pesquisa com um posfácio sempre atual de que, conforme Abreu (2001, p. 155), "o trabalho escolar tem difundido o discurso da nãoleitura muito mais do que o contribuído para a reflexão sobre as práticas de leitura", e consequentemente ou conjuntamente, pouco contribuído para o ensino de língua portuguesa. Aqui o signo saussuriano entra, e precisa ainda ser amplamente explorado.

\section{Referências}

ABREU, M. Diferença e desigualdade: preconceitos em leitura. In: MARINHO, M. Ler e Navegar. CEALE: Belo Horizonte, 2001, p. 139 - 157.

BELMIRO, C. A. Uma educação estética nos livros didáticos de português. In: ROJO, R., BATISTA, A. A. G. Livro didático de língua portuguesa : letramento e cultura da escrita. São Paulo: Mercado das Letras, 2003. p. 299-320.

BENVENISTE, É. Problemas de Linguística Geral II. Pontes: Campinas, 2006.

BOUQUET, S. Principes d'une Linguistique de L'interprétation : Une épistémologie néosaussurienne. In: Langages, L'apport des manuscrits de Ferdinand de Saussure, ํㅜ 185, 2012.

CAGLIARI, L. Alfabetização e linguística. São Paulo: Scipione,1996.

. Algumas questões de Linguística na alfabetização. In: UNIVESP, Conteúdo e Didática de Alfabetização, s/d, p. 72 a 83.

CAREL, M. L'entrelacement Argumentatif: lexique, discours et blocs sémantiques. Paris: Honoré Champion, 2011.

CLUB, Incrível. 2020. 10 brasileiros comuns que se tornaram verdadeiros super heróis. Disponível em <https://incrivel.club/inspiracao-historias/conheca-10-superherois-brasileiros-que-nao-usam-capa-730160/>. Acesso em: 15 março 2020.

DUCROT, O. ANSCOMBRE, J. C. L'argumenttion dans la langue. Paris : Mardaga, 1983.

FRADE, I. C. A. da S. Métodos e didáticas de alfabetização: história, características e modos de fazer de professores. In: CEALE, caderno do professor. Belo Horizonte: FaE/UFMG, 2007. 
FREIRE, P. Pedagogia do Oprimido. São Paulo e Rio de Janeiro: Paz e Terra, 2018.

FERREIRO, E; TEBEROSKY, A. A psicogênese da língua escrita. Tradução de D. M. Lichstenstein et. al. Porto Alegre: Artes Médicas, 1985.

FOUCAULT, M. A ordem do discurso. São Paulo: Loyola, 2009.

FORÇA MÁXIMA, Colégio. Plano de Estudo: teste 02. In: Módulos 8 - simple past, questão 2, p. 11. Disponível em <https://docplayer.com.br/50778934-Plano-deestudo-teste-02-ciencias-8o-ano-2o-trimestre.html>. Acesso em: 19 março 2020.

GOOGLE, Verbete acreditar. Acreditar. Verbete disponível em $<$ https://www.google.com.br/search? $\mathrm{q}=\mathrm{o}+\mathrm{que}+\% \mathrm{C} 3 \% \mathrm{~A} 9+$ acreditar\&oq $=\mathrm{o}+\mathrm{que}+\% \mathrm{C} 3$ \%A9+acreditar\&aqs $=$ chrome..69i57j69i59j69i60j69i59j69i6012.1935j0j8\&sourceid=c hrome\&ie=UTF-8>. Acesso em 18 mai 2018.

MACHADO, J. Era uma vez um mundo mágico que educava. In: BARBOSA, C.; MACHADO, J. (Orgs). Educação escolar: teorias e práticas. Curitiba: CRV, 2017.

NETO, A. Economia criativa: a chave para ativar um futuro abundante. In: Administradores.com. 2016. Disponível em < https://administradores.com.br/artigos/economia-criativa-a-chave-para-ativar-umfuturo-abundante>. Acesso em: 15 março 2020.

SAUSSURE, F. Cours de Linguistique Générale. Paris : Payot, 1985.

SAUSSURE, F. Écrits de Linguistique Générale. Paris : Éditions Gallimard, 2002.

SERRA, N. ; F., SAAD, R. Economia criativa: da discussão do conceito à formulação de políticas públicas. IN: RAI-Revista de Administração e Inovação. São Paulo, v. 11, No 4. 2014, p. 355 - 372. Disponível em <http://www.revistas.usp.br/rai/article/view/110253/pdf_138>. Acesso em: 15 março 2020 .

SOARES, M. Novas práticas de leitura e escrita: letramento na cibercultura. In: Educação e Sociedade, Campinas, vol. 23, n. 81, p. 143-160, dez. 2002. Disponível em < http://www.cedes.unicamp.br>. Acesso em: 15 março 2020.

. Alfabetização e Letramento. Contexto: São Paulo, 2003.

XAVIER, Glaucia do Carmo. Significante e significado no processo de alfabetização e letramento: contribuições de Saussure. In: PUC, Cadernos Cespuc, Belo Horizonte, No. 25, p. 87 - 102, 2014. Disponível em <file:///C:/Users/Livian\%20Machado/Downloads/11089-Texto\%20do\%20artigo39825-1-10-20151211.pdf>. Acesso em: 15 março 2020. 